\title{
Etnomatemática e educação escolar indígena: ensino por meio de uma atividade piscatória
}

\author{
Ethnomathematics and indigenous school education: \\ teaching through a fishing activity
}

\author{
José Roberto Linhares de Mattos ${ }^{1}$ \\ Sandra Maria Nascimento de Mattos² \\ Gamalonô Surui ${ }^{3}$
}

DOI: http://dx.doi.org/10.20435/tellus.v0i42.691

\begin{abstract}
Resumo: Este trabalho envolve a cultura da etnia Paiter Suruí e o ensino na escola indígena. Utilizamos como metodologia de pesquisa a observação participante, com características etnográficas, em uma prática piscatória tradicional, rodas de conversa e entrevistas com professores indígenas. $\mathrm{O}$ objetivo foi mostrar conexões de conteúdos curriculares da educação escolar indígena com essa prática cultural da etnia. Baseando-nos no Programa Etnomatemática, identificamos diferentes atividades que são realizadas para os conteúdos escolares, com os conhecimentos cotidianos, que empoderam o professor e seus alunos cultural, social, política e afetivamente. Constatamos, por meio de relatos de professores indígenas, que a prática cultural observada é utilizada no ensino das disciplinas Matemática, Língua Materna e Cultura Indígena.
\end{abstract}

Palavras-chave: práticas; piscatória; Etnomatemática; indígena.

Abstract: This work involves the culture of the Paiter Suruí ethnic group and the teaching in the indigenous school. As a research methodology, we used participant observation, with ethnographic characteristics, in a traditional fishing practice, conversation circles and interviews with indigenous teachers. The goal was to show connections of curricular contents in indigenous school education with this cultural practice of the ethnicity. Based in Ethnomathematics Program, we identified different activities carried out for school content, with this traditional knowledge, which empower the teacher and his students culturally, socially, politically and affectively. We have found, through reports

\footnotetext{
1 Universidade Federal Fluminense (UFF), Niterói, Rio de Janeiro, Brasil.

2 Universidade Federal Rural do Rio de Janeiro (UFRRJ), Seropédica, Rio de Janeiro, Brasil.

3 Secretaria de Educação do Estado de Rondônia, Cacoal, Rondônia, Brasil.
} 
of indigenous teachers, that the observed cultural practice is used in teach of Mathematics, Native Language and Indigenous Culture.

Keywords: practices; fishing; Ethnomathematics; indigenous.

\section{INTRODUÇÃO}

Os povos indígenas preservam tanto a fauna quanto a flora, por meio da cultura passada pelos anciãos ou sabedores, como eles os chamam, aos jovens indígenas da etnia. Seus saberes e fazeres garantem que as tradições do povo sejam resguardadas e transmitidas de geração a geração. Entre essas tradições, temos uma prática piscatória denominada "bater timbó", que é utilizada desde antes do contato com os não indígenas.

Os saberes e fazeres das etnias indígenas são protegidos por leis nacionais e internacionais, entre essas, temos como principais a Declaração das Nações Unidas sobre os Direitos dos Povos Indígenas (Drips) (ONU, 2008), que garante a revitalização da cultura e o direito à educação de acordo com seus métodos culturais; e a Constituição Federal Brasileira (BRASIL, 1988), que reconhece os indígenas, em suas diferentes etnias, como organização social com costumes, crenças e tradições próprias.

Com mesmo grau de importância, temos, no que diz respeito à educação escolar indígena propriamente dita, a Lei de Diretrizes e Bases da Educação Nacional (Ldben), n. 9.394/96 (BRASIL, 1996), que afirma que a educação escolar indígena deve ser intercultural, bilíngue e diferenciada, preservando assim a identidade, os costumes e as tradições de cada etnia. O Referencial Curricular Nacional para as Escolas Indígenas (Rcnei) (BRASIL, 1998) e as Diretrizes Curriculares Nacionais para a Educação Escolar Indígena da Educação Básica (Dcneei) (BRASIL, 2013) asseguram, além de um currículo prescrito, um viés local, priorizando anseios, necessidades e interesses das comunidades indígenas.

Baseados nessas leis, em autores como D’Ambrosio (2011, 2008), Domite (2009), Vergani (2007), Scandiuzzi (2009), Grupione (1994), Gallois (2006), Sampaio (2006), Mattos (2020), Mattos e Ferreira Neto (2019, 2016), Mattos e Mattos (2019, 2018), Mattos (2018), Mindlin (1985, 2006) e nas próprias experiências da etnia Paiter Suruí sobre as práticas piscatórias, em especial o bater 
timbó, realizamos uma pesquisa de campo com características etnográficas, com observação participante e conversas com membros da etnia. O objetivo foi identificar conteúdos escolares, em especial de matemática, explorados pelo professor indígena em sala de aula, relacionados com a tradicional pescaria de bater timbó. Nessa perspectiva, antes de buscar as atividades matemáticas inerentes à pescaria, fomos entender como essa prática era desenvolvida de acordo com a tradição dos Paiter Suruí. Para isso, participamos da pescaria tradicional de bater timbó que foi realizada em dois dias em um rio na Floresta Amazônica.

De acordo com o que observamos, foi possível identificar algumas atividades relacionadas à matemática, bem como a outras diferentes disciplinas que o professor indígena trabalha em sala de aula. O saber notório impregnado na prática piscatória de bater timbó dos Paiter Suruí, desde o dia anterior até a finalização desta, no dia seguinte ao início da pesca, deixa-nos antever conexões com o ensino e a aprendizagem tomando por base o Programa Etnomatemática. Dá um novo olhar para uma prática desenvolvida com naturalidade desde os primórdios da etnia. Ao realizá-la, os Paiter Suruí conseguem preservar a cultura, retiram o alimento que é distribuído para os membros participantes, asseguram a língua materna e resguardam as histórias, os cantos e os mitos que envolvem tal prática.

Verificamos a preocupação com a sustentabilidade e a preservação da floresta, da fauna e da flora, já que é tradição do povo assegurar que as futuras gerações tenham acesso à mesma biodiversidade encontrada atualmente. Observamos que essa pescaria é realizada coletivamente e envolve tanto homens como mulheres, cada qual com seus afazeres. Assim, tomamos como justificativa a necessidade de adequar a matemática acadêmica à vivência da etnia para possibilitar uma ressignificação da matemática escolar. Em suma, pudemos constatar que os saberes e fazeres da etnia são repletos de uma matemática própria que pode ser levada para a sala de aula, pelo professor indígena, para ressignificar a matemática escolar. Dessa forma, a aprendizagem dos alunos torna-se mais atraente, envolvente e significativa, por estar contextualizada na cultura da etnia.

\section{OS PAITER SURUÍ E A EDUCAÇÃO (ESCOLAR) INDÍGENA}

Paiter Suruí de Rondônia é um povo indígena que ocupa a Terra Indígena (TI) Sete de Setembro, demarcada, nos estados de Rondônia e Mato Grosso, com 
uma extensão aproximada de $2.478 \mathrm{~km}^{2}$, tendo aldeias nos dois estados. Fala um idioma da família linguística Mondé, do tronco linguístico Tupi. Conforme o cacique da aldeia Paiter Linha 09, a palavra Paiter, que os não indígenas consideram significar "gente de verdade" (MINDLIN, 1985, p. 13), na realidade, significa "gente". Segundo ele, "Paiter Iter que significa gente de verdade". Porém, por uma simplificação na fala, eles são conhecidos como "Paiter". Após o contato com não indígenas, eles passaram a ser chamados, também, de Suruí.

A TI Sete de Setembro tem 27 aldeias, sendo 25 delas registradas pela Fundação Nacional do Índio (Funai), distribuídas por "estradas vicinais", denominadas "linhas". A aldeia Paiter Linha 09, na cidade de Cacoal, RO, foi aberta em 1982 por duas famílias e, atualmente, há 26 famílias, com um total de 197 pessoas, sendo a segunda maior aldeia da etnia. O nome Sete de Setembro teve sua origem devido ao nome do acampamento da Funai que foi criado no dia sete de setembro de 1968, exatamente um ano antes do primeiro contato.

Os afazeres cotidianos da aldeia são divididos entre homens e mulheres. São destinados às mulheres os afazeres da casa, o cuidado com as crianças e a produção de artesanato. As mulheres são responsáveis pela produção de peças artesanais em cerâmica, como a confecção de panela de barro, pelas cestarias e por tecer o algodão. O algodão é utilizado na confecção de redes, tipoias para carregar as crianças de colo, cintas e colares, bem como para utilizar no arco e flecha. Aos homens, são destinadas as atividades de caça, pesca (mulheres também podem pescar, não sendo com arco e flecha), construção de roças e confecção do arco, flecha e cocares.

A aldeia Paiter possui uma escola, chamada Escola Indígena Estadual Izidoro de Souza Meireles. Esta escola entrou em funcionamento em 1987, originalmente com o ensino fundamental. A partir de 2014, passou a ter o ensino médio, tendo sua primeira turma formada em 2016, com sete alunos. Conta com cinco professores indígenas e 13 professores não indígenas que atuam por revezamento. Em 2017/2018, atuavam na escola sete professores não indígenas. A escola tinha 35 alunos no ensino fundamental e 13 alunos no ensino médio.

A escola trabalha, no ensino fundamental, com a Pedagogia de Projetos, por meio do Projeto Mais Educação do governo federal. O Projeto Mais Educação visa fomentar, por meio de sensibilização, incentivo e apoio, outros projetos e ações 
de articulação de políticas sociais e implementação de atividades socioeducativas, oferecidas gratuitamente às crianças, adolescentes e jovens, para o fortalecimento cultural e o uso da língua Paiter. Agroecologia, cultura, artes, memória e histórias das comunidades tradicionais, artesanatos e acompanhamento pedagógico são as áreas desse projeto, que são trabalhadas na escola. Nessa perspectiva, o Projeto Mais Educação fortalece o trabalho do professor indígena em sala de aula, valorizando a cultura, a memória e a história do povo, por meio da participação e das práticas dos idosos, sabedores dos conhecimentos socioculturais da etnia.

A introdução da cultura, história, saberes e fazeres da etnia Paiter Suruí na escola não significa rejeição à cultura do não indígena em suas práticas escolares, mas um resgate do respeito e da valorização da identidade deles. Dessa forma, corrobora D’Ambrosio (2011, p. 43), quando este afirma que "conhecer e assimilar a cultura do dominador se torna positivo desde que as raízes do dominado sejam fortes". E, mais ainda, a "boa matemática acadêmica" (D’AMBROSIO, 2011, p. 43) só se torna boa para um povo quando ela se faz presente crítica e reflexivamente e se torna eficaz para o povo que pode percebê-la em suas práticas diárias.

O Programa Etnomatemática tem abraçado esse viés de respeito para com as culturas dos diferentes povos e etnias, conferindo dignidade aos saberes e fazeres produzidos e difundidos por eles. Segundo Vergani (2007, p. 32), "há uma ética associada ao conhecimento matemático, cuja prática é guiada pelo conhecimento de nós próprios, pela diluição das barreiras entre indivíduos, pela construção de uma harmonia ancorada no respeito, solidariedade e cooperação". Assim sendo, a plenitude de alunos e professor está associada à sua realidade sociocultural e ambiental.

Corrobora, ainda, Scandiuzzi (2009, p. 17), quando afirma que devemos "olhar para o indivíduo integral", inserido em um meio que se relaciona com outros socioculturalmente, e que cada qual tem uma história específica. Mas não podemos nos esquecer de que o meio ambiente desse povo "está inserido em outros meios ambientes", exigindo do professor "a busca do(s) caminho(s) escolhidos(s) e desejado(s) por esses indivíduos e/ou sociedades". Bicho (2018) reconhece que a Etnomatemática auxilia os professores indígenas a refletirem e planejarem práticas pedagógicas que marquem o lugar dos saberes e fazeres tradicionais indígenas. De acordo com o autor, "a Etnomatemática pode contribuir com o ensino da matemática escolar, uma vez 
que acena para o reconhecimento, valorização e dinamização cultural" (BICHO, 2018, p. 179), desconstruindo o ensino ocidental e abrindo espaço para práticas docentes que incorporem os conhecimentos indígenas.

\section{PRÁTICAS PISCATÓRIAS DOS PAITER SURUÍ: SABERES E FAZERES ANCESTRAIS}

Os saberes e fazeres indígenas guardam os valores, as crenças e os costumes que são passados pela cultura oral desse povo. Esses saberes e fazeres são formas de preservar, valorizar e garantir a transmissão dos hábitos tradicionais da etnia aos jovens. O manejo com a terra, o preparo da roça, a região e época de pesca são alguns desses saberes e fazeres que são desenvolvidos de maneira sustentável. Passar a tradição aos jovens é direito assegurado pela Drips (ONU, 2008), em que seus artigos 11 e 12 garantem a prática e revitalização de suas tradições e costumes culturais. Da mesma forma, o artigo 31 garante "o direito de manter, controlar, proteger e desenvolver o patrimônio cultural, seus conhecimentos tradicionais, suas expressões tradicionais e suas manifestações [...]" (ONU, 2008, p. 16), entre elas, a tradição oral para assegurar a propriedade intelectual do patrimônio cultural. É garantido, também, nos artigos 14 e 15, o direito à educação em consonância com seus métodos culturais de ensino e de aprendizagem, refletindo a diversidade cultural, suas histórias e suas tradições.

Segundo Grupioni (1994, p. 23), os indígenas não só defendem a natureza como são parte dela, "vivendo integrados à natureza, são ecológicos em essência e, assim, devem ser protegidos e preservados" tanto em sua cultura como em sua forma de manter as tradições e os costumes de alimentação. Sua sobrevivência depende do equilíbrio entre os saberes e fazeres ancestrais com a natureza. Para Gallois (2006, p. 80), "Um inventário de tradições culturais remete diretamente a questões metodológicas relacionadas à produção de conhecimento. Entre essas questões, uma das mais interessantes é a relação entre conhecimento e prática". Nesta perspectiva, as práticas piscatórias dos Paiter Suruí agregam saberes e fazeres restritos ao seu povo, renovado pela oralidade e pela prática aos seus descendentes.

De acordo com Sampaio (2006, p. 165 grifos do autor), "a cultura indígena aparece como o domínio social por excelência através do qual tais valores se expressam e a escola indígena como a via institucional para sua formalização e reprodução". 
Portanto o manejo piscatório faz parte da cultura indígena e sua preservação depende tanto da prática como da transmissão oral dos sabedores culturais. Ressaltamos que, após o contato com o não indígena, os Paiter Suruí apresentaram mudanças em suas tradições. Entretanto alguns hábitos continuam sendo desenvolvidos do mesmo jeito que o eram antes desse contato, como é o caso de algumas práticas piscatórias. Práticas essas perpetuadas pela necessidade de sobrevivência, preservação ambiental e manutenção da alimentação de subsistência.

O manejo ambiental do território indígena e a preservação da biodiversidade estão imbricados na cotidianidade sociocultural, sobretudo na sabedoria ancestral de como realizar a pesca. O peixe, alimento apreciado pelos indígenas, é importante para garantir a nutrição dos povos, mas, se não for preservado, pode entrar em extinção. Na etnia Paiter Suruí, as técnicas tradicionais para pescar são o arco e flecha e o bater timbó em épocas de seca. Tanto os homens como as mulheres realizam o bater timbó. Após o contato, houve o acréscimo da pesca com anzol, tarrafa e rede. A zona de pesca, o Morip ey Pãyah, é descrita como a região resguardada ao longo dos rios e igarapés onde o povo indígena Paiter Suruí realiza a pesca.

Este etnozoneamento é desenvolvido para a preservação da biodiversidade local. Geralmente, é realizada a pesca de subsistência, em que os indígenas adquirem o necessário ao consumo da família. Essa pesca é realizada de novembro a junho e somente com arco e flecha. Se atentarmos para a época realizada com arco e flecha, observamos que ela ocorre no período da desova dos peixes amazonenses, que varia de setembro a junho. É, portanto, uma forma de preservação dos ninhos reprodutivos e dos peixes em desenvolvimento, já que podem escolher qual peixe pegar, o que é uma maneira sustentável de garantir alimento para as gerações futuras.

No dia anterior à pescaria de bater timbó, os indígenas apanham o cipó de uma planta conhecida por eles como Markap, que é cortado em pedaços a serem armazenados em sacos. Pegam, ainda, cascas da árvore conhecida como Ibirema ou da árvore Parãh (palmeira barriguda), com as quais serão elaboradas as circunferências onde será inserido o cipó, juntamente de algumas outras cascas de outra árvore conhecida por Tamburi. Constatamos que são utilizados três tipos de espécies nativas da floresta. Entretanto há o cuidado em não as arrancar, somente retiram o que vai ser utilizado na pescaria. 
Para bater timbó, é necessário ter o conhecimento dos sabedores desde a escolha do cipó até a pesca propriamente dita. O timbó é uma planta da região norte do país. É um tipo de cipó que contém uma substância capaz de impedir a respiração dos peixes, asfixiando-os até a morte ou quase, quando eles ficam atordoados. Conhecido como tinguijada, o cipó timbó é cortado em pedaços, os quais são amarrados e, já dentro da água, golpeados por um pedaço de madeira para liberar a substância. É uma técnica realizada pelos Paiter Suruí em época de águas baixas, quando ocorre maior diluição da substância e menor dispersão na água.

Os peixes atordoados ou mortos ficam na superfície e são capturados com as mãos. Segundo a cultura Paiter, não se pode ficar na margem do rio olhando o peixe morrer, quando está batendo timbó, pois, senão, os peixes não morrem ou então afundam no rio e não são pegos. De acordo com um indígena Paiter Suruí: "O processo de bater timbó é um método de pesca tradicional do povo Paiter, ou seja, é um costume deste povo". Portanto, esse costume é passado de geração a geração como técnica piscatória, realizada somente na época de baixa das águas dos rios e igarapés. Ainda, segundo esse indígena, prevalece o costume na cultura da etnia e "mesmo sabendo que afeta o rio [...]" ocorre essa prática até os dias de hoje. Há, entretanto, o cuidado de realizá-la em épocas apropriadas. Segundo esse indígena, "o mês ideal de bater timbó é de julho a agosto. Nesta época, o rio fica bem estreito, principalmente igarapé", minimizando assim a dispersão da substância nas águas.

Desse modo, eles compreendem que bater timbó mata qualquer tipo de peixe, "mas quando começa a chover, o rio enche e traz tudo de novo, os peixes, por isso o Paiter precisa conhecer a nascente do rio ou do igarapé antes de bater o timbó" (relato de um indígena Paiter Suruí, 2018). Os Paiter Suruí reconhecem que a preservação dos recursos hídricos existentes na região é de suma importância para que os peixes se reproduzam e, consequentemente, assegurem alimentação para as gerações futuras. Por isso, torna-se essencial passar aos mais jovens como realizar o bater timbó, onde e porque fazê-lo. Um indígena afirma: "Se for minas de água", que têm alguns lambaris, não é recomendado bater timbó. Só pode aquele igarapé que tem condição de encher de novo na época da chuva".

\footnotetext{
${ }^{4}$ Entendemos minas de água como nascente ou cabeceira de rios e igarapés, em outras palavras, é o local onde tem início o curso d'água. É o aparecimento na superfície de um lençol subterrâneo d'água, originando os rios, riachos, córregos, igarapés etc.
} 
Ressaltamos que a época de bater timbó, restrita aos meses de julho e agosto, é respeitada por todos, como nos conta um indígena: "Diz Paiter, se acontecer bater timbó mais cedo da época seca, por exemplo, mês de junho, daí provoca chuva, e também bater timbó quando rio está cheio não dá efeito para matar os peixes, porque a quantidade da substância que sai do timbó fica pouco para água". Assim, eles preservam a desova dos peixes nos ninhos reprodutivos que ocorre na época da cheia.

Em depoimento, um indígena afirma: "Por isso quando a água está bem estreita, quase secando, a quantidade da substância fica equilibrada com a água. Daí dá efeito aos peixes". Esta técnica piscatória sempre foi realizada pelos Paiter Suruí, sendo uma técnica remanescente dos costumes e tradições da etnia. Porém eles priorizavam a pesca com flecha antes do contato com o não indígena, como pudemos constatar neste depoimento: "Lembrando, época da chuva, Paiter antes do contato com a sociedade envolvente sempre pescava com flecha". Após o contato com o não indígena, a preocupação está nas práticas ilegais na região, que provocam alterações climáticas.

\section{ASPECTOS METODOLÓGICOS E OS CAMINHOS QUE ORIENTARAM A PESQUISA}

Uma pesquisa sempre é direcionada por alguns aspectos metodológicos, os quais envolvem a escolha de caminhos que a orientarão. Partindo do objetivo de pesquisa que era mostrar conexões de conteúdos escolares da educação escolar indígena com a prática piscatória bater timbó da etnia Paiter Suruí, deparamo-nos com práticas docentes já desenvolvidas por professores indígenas, nas quais havia relação com essa atividade tradicional e cultural da etnia. Portanto esse recorte faz parte de uma pesquisa maior sobre a etnia Paiter Suruí e o desenvolvimento de práticas docentes que reportem às atividades e aos conhecimentos tradicionais desse povo.

Observamos que se trata de um estudo de caso, por entendermos que, nesse tipo de abordagem, recolhem-se e analisam-se provas empíricas, bem como se focaliza nos fenômenos e acontecimentos dentro do contexto da vida real. De acordo com Yin (1994), um estudo de caso "é um inquérito empírico que investiga um fenômeno contemporâneo dentro do seu conceito de vida real, especialmente quando as fronteiras entre fenômeno e contextos não são claramente evidentes" (YIN, 1994, p. 
24). Isso significa que estamos perpassando o contexto de pesquisa, articulando-nos com os sujeitos envolvidos, para o desenvolvimento de conhecimentos acerca das práticas docentes elaboradas pelos professores indígenas da aldeia.

Não podemos relatar sistematicamente como foram desenvolvidas essas práticas docentes, mas podemos ressaltar que elas foram abordadas pelos professores como estratégias para ressignificar os conteúdos matemáticos escolares, que, segundo os próprios professores, são atividades realizadas cotidianamente e que fazem parte dos saberes e fazeres da etnia. Portanto o trabalho de campo desses professores com seus alunos ocorre naturalmente, sem necessidade de sistematização ou quaisquer outros modelos que estamos acostumados a realizar em uma pesquisa. Entretanto, como cientificamente necessitamos fazê-la, recorremos aos relatos desses professores e constatamos que a utilização em sala de aula dessa prática piscatória envolve reviver o vivido cotidianamente por todos, ou seja, a própria prática.

Utilizamos alguns instrumentos de pesquisa, tais como a observação participante direta, realizada em uma atividade tradicional da etnia Paiter Suruí; a captação de imagens e áudios por meio de rodas de conversa e entrevistas; e a utilização de um diário de campo, no qual registramos os acontecimentos diários e nossas impressões a respeito desses acontecimentos. A convivência de alguns anos com o povo Paiter possibilitou-nos participar da prática piscatória de bater timbó, aspecto essencial para compreendermos os saberes e fazeres envolvidos em tal prática. Possibilitou-nos, ainda, um maior entrosamento com os sujeitos de pesquisa selecionados, que foram os professores indígenas, alguns sabedores e alguns outros membros da etnia. Os autores são profundos conhecedores da cultura Paiter, sendo um deles indígena morador na aldeia.

A análise e as discussões dos dados recaíram sobre o que foi relatado pelos sujeitos de pesquisa e nossas observações em campo. Em uma pesquisa qualitativa, a coleta de dados não se realiza separadamente. Há um intercâmbio entre os diferentes instrumentos, as impressões dos pesquisadores e as respostas dos participantes para a estruturação das análises e dos resultados encontrados. Existem, em uma pesquisa qualitativa, alguns critérios que devem ser seguidos quando se utilizam variados instrumentos, os quais sofrem triangulação que possibilita as discussões pertinentes ao que se pretender atingir. 
A transformação do material recolhido em dados envolveu organizar, categorizar e analisar respostas. A produtividade ocorrida na análise das respostas obtidas está na apreensão da subjetividade contida, latente ou subentendida, nas mensagens expressas pelos sujeitos de pesquisa. Diante disso, a análise dos dados baseou-se no referencial teórico e nas informações coletadas. Os resultados apontam para a necessidade de aliar a cultura do povo Paiter Suruí às práticas docentes realizadas em sala de aula e que isso já vem acontecendo na escola da aldeia.

Esses resultados são corroborados por Mattos e Ferreira Neto (2019, p. 166), quando afirmam que "para a escola indígena, o saber, não só de matemática, deve estar a serviço de sua comunidade, respondendo aos seus anseios e atendendo as suas demandas, formando as crianças e jovens de acordo com seus ideais e padrões culturais". Para que isso ocorra, os professores indígenas devem possuir formação, no caso licenciatura intercultural, e ter respeito e comprometimento com a própria cultura e com seu povo.

Mattos (2020, p. 99) também nos ajuda na reafirmação dos resultados quando afirma que o sentido e os significados atribuídos pelos membros de um grupo encontram-se "[...] interligados pela cultura que se relaciona aos sentimentos, ao sentido de pertencimento que revela a identidade de cada um e do grupo social e aos conceitos, valores e ideias compartilhados". O papel que cada um assume dentro da comunidade é o que os torna socialmente reconhecidos pelos demais. Consequentemente, os professores indígenas da aldeia Paiter tomaram posse desse papel para resguardar a própria cultura.

\section{EDUCAÇÃO ESCOLAR INDÍGENA: PRESERVAÇÃO DA BIODIVERSIDADE E SUSTENTABILIDADE}

Competência do Ministério da Educação do Brasil (MEC), a educação escolar indígena é realizada de forma específica, diferenciada, intercultural, bilíngue e comunitária. Referenciada por legislação específica, a começar pela Constituição Federal de 1988 (BRASIL, 1988), reconhecendo os indígenas como organização social com costumes, crenças e tradições próprias, em que a educação escolar deve assegurar a língua materna e processos próprios de ensino e de aprendizagem. Em 1991, a Portaria Interministerial n. 559, de 16 de abril, em seu art. 4으, criou a Coordenação Nacional da Educação Indígena (Cnei), com a finalidade de coordenar, 
acompanhar e avaliar as ações pedagógicas da Educação Indígena no País. Já no art. 5o é estimulada a criação dos Núcleos de Educação Escolar Indígenas (Neei), com a finalidade de apoiar e assessorar as escolas indígenas (BRASIL, 1991) em sua regularização, bem como assegurar a formação docente. Em 1993, foram instituídas as Diretrizes para a Política Nacional de Educação Escolar Indígena (BRASIL, 1993), reafirmando a especificidade dessa educação.

Houve avanço significativo referente à educação escolar indígena, mas é com a Lei de Diretrizes e Bases da Educação Nacional (Ldben), de 1996 (BRASIL, 1996), em seus artigos 26, 32, 78 e 79, que se afirma ser a educação escolar indígena intercultural e bilíngue, preservando às etnias sua identidade, seus costumes e suas tradições. O lançamento do Referencial Curricular Nacional para as escolas indígenas de 1998 (BRASIL, 1998) assegurou um currículo local, priorizando os anseios e interesses das comunidades indígenas. Assim, a educação escolar indígena se faz comunitária, valorizando seus princípios e concepções; intercultural, reconhecendo a diversidade cultural e linguística das etnias; bilíngue, dando oportunidade em aprender a língua materna e o português; e diferenciada, refletindo as particularidades e autonomia de cada etnia.

Ressaltamos que a educação dos povos indígenas não se realiza somente pela educação escolar indígena. A educação indígena sempre existiu por meio da transmissão oral e da prática. Naturalmente, cada etnia encontra sua maneira de passar aos mais jovens os costumes, as crenças, os valores e as tradições. Geralmente, os anciãos transmitem os saberes e fazeres ancestrais, tais como os mitos e os rituais, manejo e confecção dos instrumentos de caça e pesca, artesanatos, cestarias etc. Não há sistematização nesse tipo de educação, mas ela é importante para a preservação de técnicas e costumes tradicionais de cada etnia. Qualquer indígena pode ensinar algo no dia a dia da comunidade, e esses saberes podem ser utilizados pelo professor indígena em sala de aula, pois, de acordo com Mattos e Ferreira Neto (2016, p. 84):

É bom atentarmos para a naturalidade do implemento da realidade do aluno dentro da sala de aula. A prática educacional embebida da realidade vivenciada em uma aldeia torna as aulas para o aluno indígena, mais atrativas e interessantes, pois esse estudante passa a vivenciar na prática tudo aquilo que o rodeia diariamente. 
Nesta perspectiva, existe na grade curricular das escolas indígenas duas disciplinas voltadas para preservação da cultura da etnia. A primeira, Cultura do Povo, que contempla as tradições, mitos e rituais indígenas, e a segunda, Língua Materna, que ensina a linguagem do povo a que pertence. Na etnia Paiter Suruí, para saber o que ensinar na primeira disciplina, o professor vai às casas realizar pesquisa. Faz uma enquete sobre o que ensinar e, assim, de acordo com a comunidade local, são escolhidos os temas. Desse modo, é na primeira disciplina que se ensina, entre outros saberes e fazeres, as técnicas piscatórias.

Há dois momentos de ensino dessas técnicas, conforme nos explicou um professor indígena. O primeiro momento, teórico, realizado em sala de aula, que utiliza os conhecimentos da pesca com flecha e do bater timbó para contextualizar conteúdos escolares. O segundo momento, prático, é diferenciado. Para o bater timbó, o professor, três sabedores da cultura e os alunos, quando vão realizar a pesca propriamente dita, organizam-se segundo o rio e os igarapés que podem utilizar para esse tipo de pesca. Ao final do processo, os alunos realizam as transcrições do que fizeram em campo e, para ajudá-los, um sabedor vai à sala de aula falar sobre mito e tradição do povo. Isso faz parte do Projeto Mais Educação da aldeia Paiter.

Para pesca com flecha, é realizada pesquisa junto aos pais, avôs ou tios. Muitas vezes, os pais saem com os filhos para pescar com flecha e, consequentemente, há o aprendizado dessa técnica naturalmente. Na aula teórica sobre a pesca com flecha, é ensinado sobre o material utilizado para confeccionar o instrumento. O material adequado para produzir o arco e a flecha é um tipo de taquara, chamada Makor (Taboca), muito encontrada no estado de Mato Grosso. Em Rondônia, atualmente, é difícil encontrar esse tipo de taquara, que era avistada em Espigão do Oeste, mas eles já estão optando por novos tipos de materiais. Para a confecção da ponta da flecha, os Paiter Suruí retiram o yapeh ou yapeh ohp ah (yapeh vermelho), espécies de plantas que nascem próximas aos rios e são encontradas na Terra Indígena, na parte de Mato Grosso. A flecha é um instrumento utilizado para caçar e para guerrear contra os inimigos. Esses tipos de utilizações também são ensinados na escola.

Na pesca realizada com o anzol, introduzida após o contato, a inovação que os Paiter Suruí trouxeram foi a introdução da isca, que é o Kadeg, uma larva retirada do coquinho do babaçu e, também, considerada uma iguaria típica da etnia. 
Esse tipo de pesca é muito utilizado pela etnia, sendo uma técnica desenvolvida individualmente e que pode ser realizada tanto por homens como por mulheres.

\section{ETNOMATEMÁTICA NA PRÁTICA PISCATÓRIA DE BATER TIMBÓ DA ETNIA PAITER SURUÍ: CONHECIMENTOS TRADICIONAIS E ESCOLARES}

Ao trabalhar com as práticas piscatórias na aula de Matemática, o professor não fica preso somente a uma disciplina, pois esta ocorre interdisciplinarmente. Dessa maneira, o professor vai aliando a matemática ao desenho sobre tudo que foi desenvolvido na pescaria; ao espaço sobre os percursos desenvolvidos até chegar ao local da pesca; a botânica sobre as espécies da floresta que são utilizadas na pescaria; a cultura por meio das histórias e dos mitos que cercam esse tipo de prática piscatória, como a palmeira barriguda, a qual eles dizem que existe um indígena sem uma perna preso em seu interior.

Como o bater timbó é uma prática tradicional que contém inúmeros saberes e fazeres, várias atividades relacionadas a ela são desenvolvidas por alguns professores indígenas em suas práticas docentes. Professores indígenas identificam formas de trabalhar conteúdos matemáticos em sala de aula, o que nos leva a crer que procedimentos etnomatemáticos ocorrem, mesmo que alguns possam não ter conhecimento. Isso corrobora Cunha e Cunha (2018, p. 94), quando afirmam que "o reencontro do professor indígena com sua história, durante seu processo de formação (inicial ou em serviço), aparece como elemento fundamental para que possa dar conta do seu papel como protagonista de uma escola voltada para dentro".

Dessa forma, compreendemos que o papel dos professores indígenas como mantenedores da cultura, auxiliados pelos sabedores, possibilita-os realizar diversas atividades escolares com os alunos. Em nossa caminhada pela floresta até chegar ao local da pesca, um professor indígena comentou sobre o fato de eles cortarem o cipó e arrumarem os pedaços em sacos de $60 \mathrm{~kg}$, para levarem ao local em que vão bater o timbó. O tamanho de cada pedaço do cipó é de, aproximadamente, $40 \mathrm{~cm}$ (Figura 1). Ele nos disse que uma atividade de sala de aula para os alunos diz respeito à razão e proporção, envolvendo a quantidade de pedaços que cabem em um saco e o número de sacos necessários para carregar todo o cipó. 
Figura 1 - Cipó para ser amarrado e utilizado na pescaria de bater timbó

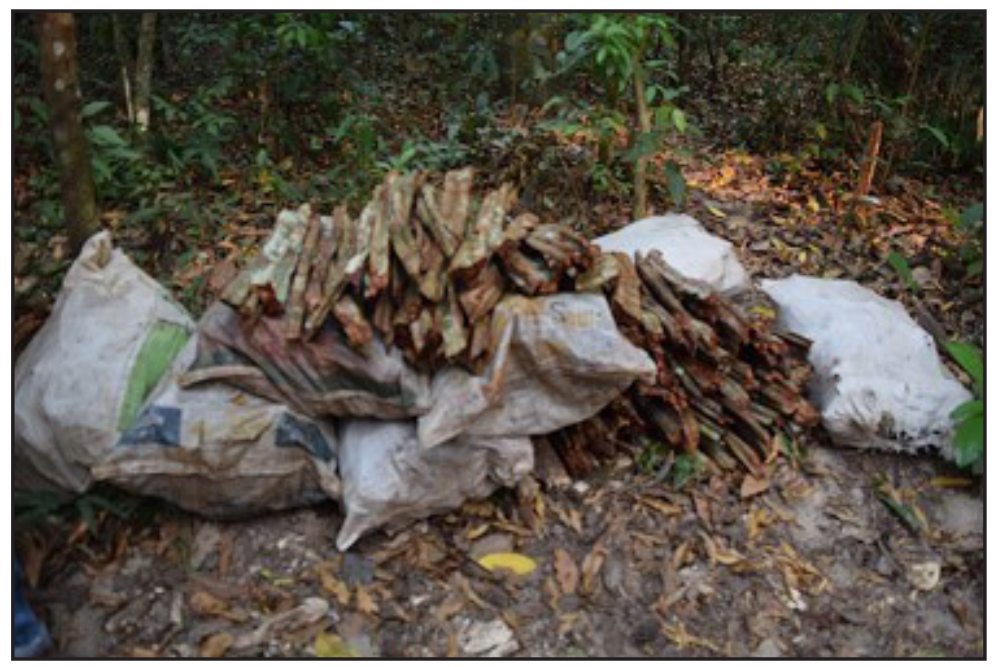

Fonte: Autores.

Antes de iniciar a pescaria, é feita a limpeza de uma área na mata, local no qual as mulheres colocam as redes, preparam a comida para todos e, também, armazenam água e café que será servido aos que estão batendo timbó. A limpeza é feita retirando pequenos galhos e matos, cortados com terçado (tipo de facão grande), que possam atrapalhar o preparo da comida. O tamanho da região é estimado pela quantidade de pessoas que participa da pescaria. Essa estratégia de natureza matemática de estimar o tamanho de uma região é usada pelos Paiter e outros povos indígenas na limpeza de um local para fazerem uma horta.

Também, há a necessidade de recolher uma certa quantidade de cipó para que haja uma boa concentração da substância na água, a fim de ocorrer a asfixia dos peixes. Quanto maior for a quantidade de água, maior deverá ser a concentração. Assim, em um igarapé, é menor a quantidade de timbó utilizado do que para um rio. Todas as estimativas são realizadas pelos sabedores, por exemplo, a circunferência para colocar o timbó, que tem aproximadamente $30 \mathrm{~cm}$ de diâmetro, é produzida por um sabedor antes de serem colocados os pedaços de cipó.

Na Figura 2, temos um sabedor indígena inserindo o timbó em uma circunferência que ele amarrou, cujos tamanhos dos pedaços dos cipós e o diâmetro da circunferência foram estimados, por ele, com o palmo. O professor indígena 
informou que essa circunferência é utilizada como contextualização em sala de aula, para ensinar raio, diâmetro, comprimento e área do círculo.

Nessa ótica, o professor indígena leva para sala de aula um aspecto do cotidiano da pescaria de bater timbó para contextualizar conceitos da matemática escolar. Entendemos que, mesmo sem saber, o professor indígena está praticando um ensino que leva à aprendizagem significativa (AUSUBEL, 2000), pois, de acordo com Mattos e Mattos (2019), o conhecimento adquirido ancora-se na estrutura cognitiva dos alunos, afetando-os e possibilitando a organização mental e o armazenamento sequenciado desse conhecimento, já que este foi contextualizado, em parte, na cultura deles.

Figura 2 - Sabedor ensinando a confecção do amarrado de timbó

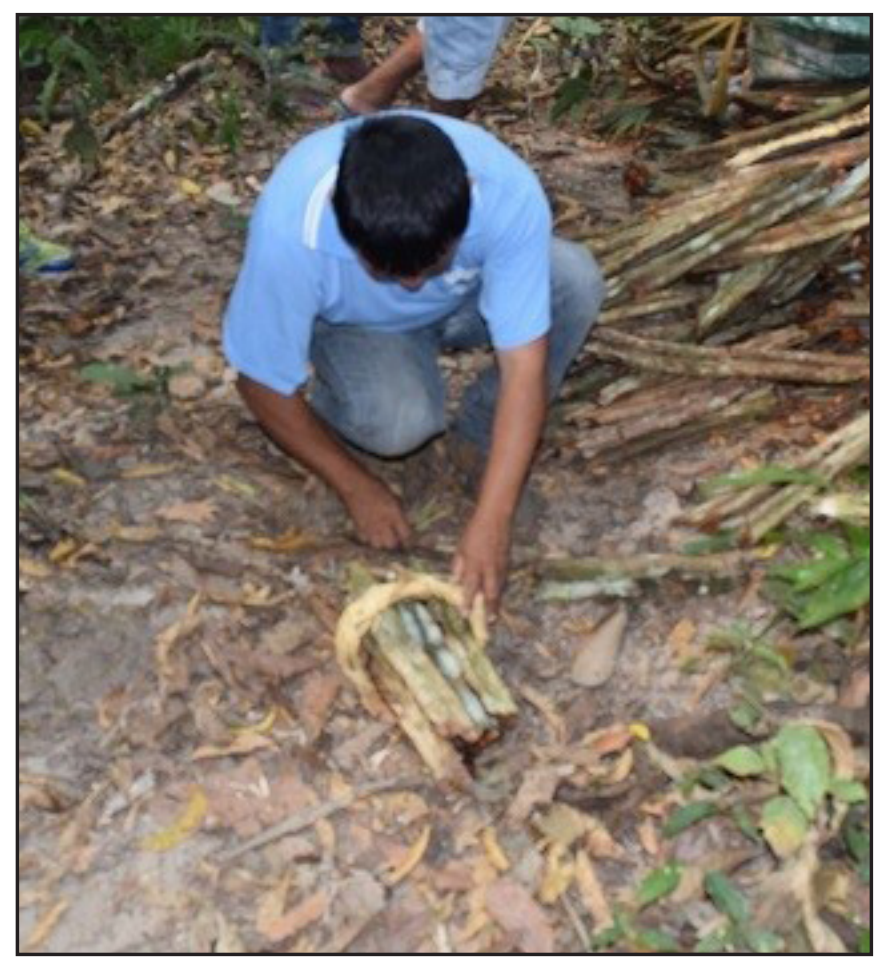

Fonte: Autores.

Voltando a nossa experiência na participação da pescaria de bater timbó, observamos que alguns indígenas ficam posicionados em locais apropriados para pegar os peixes atordoados que tentam escapar. Uma estratégia utilizada por eles 
é a colocação de redes em duas extremidades do rio ou igarapé, como observamos na Figura 3. A escolha do local em que serão posicionadas as redes depende da quantidade de água e da concentração da substância nela. Nos extremos, onde serão colocadas as redes, deve-se estar atento até onde esta substância pode alcançar. Portanto, segundo o professor indígena, estimar essa distância é importante na prática da pescaria de bater timbó.

Figura 3 - Colocação da rede para a pesca de bater timbó

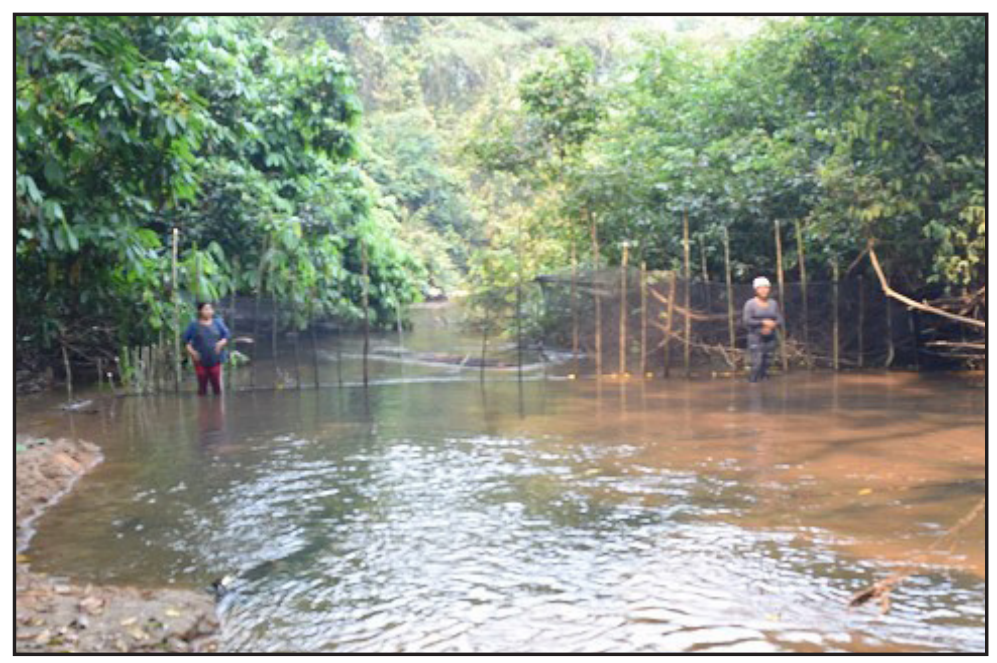

Fonte: Autores.

Constatamos que é possível contextualizar conteúdos escolares com os conhecimentos já estabelecidos pelos alunos em seu cotidiano na aldeia. Para Mattos (2020, p. 70), "a contextualização está diretamente vinculada ao conhecimento de origem do conteúdo e/ou dos alunos e a sua aplicação na realidade, na qual os estudantes estão inseridos". É interessante notar que o professor indígena reconhece a contextualização, em sua prática docente, como uma maneira de facilitar a aprendizagem dos alunos, aspecto importante quando se utilizam manifestações matemáticas, de acordo com o Programa Etnomatemática, estabelecido por D'Ambrosio (2011), que nos alerta que a contextualização é essencial para qualquer programa de educação com povos tradicionais. Em uma prática docente que utilize trajetórias hipotéticas de aprendizagem, o professor vai elaborar um conjunto de tarefas de ensino, de tal modo organizadas, que 
ativem as ações mentais dos alunos e os levem à aprendizagem significativa (MATTOS, 2020).

Observamos que os amarrados de timbó são colocados em cima de pedras que estão dentro do rio. Um indígena bate no amarrado e outro joga água; desta forma, a substância do timbó cai na água, que fica repleta de espuma e escurece. Em alguns lugares, em que as pedras estão afastadas, há a necessidade de colocar dois troncos de árvores juntos, apoiados em duas pedras ou em uma pedra e na margem do rio, que servirão de suporte para colocar os amarrados de cipó. Esses troncos são cortados e carregados pelos indígenas mais jovens. Na Figura 4, podemos ver os indígenas batendo timbó sobre os troncos de árvores e pedras. Eles relataram que o tronco escolhido precisa ser um pouco maior que a distância entre a pedra e a extremidade do rio, para dar firmeza na hora de bater timbó e dar segurança aos indígenas. Essa margem de segurança tem a função de garantir que o tronco não caia e não os machuque.

Figura 4 - Duplas de batedores de timbó

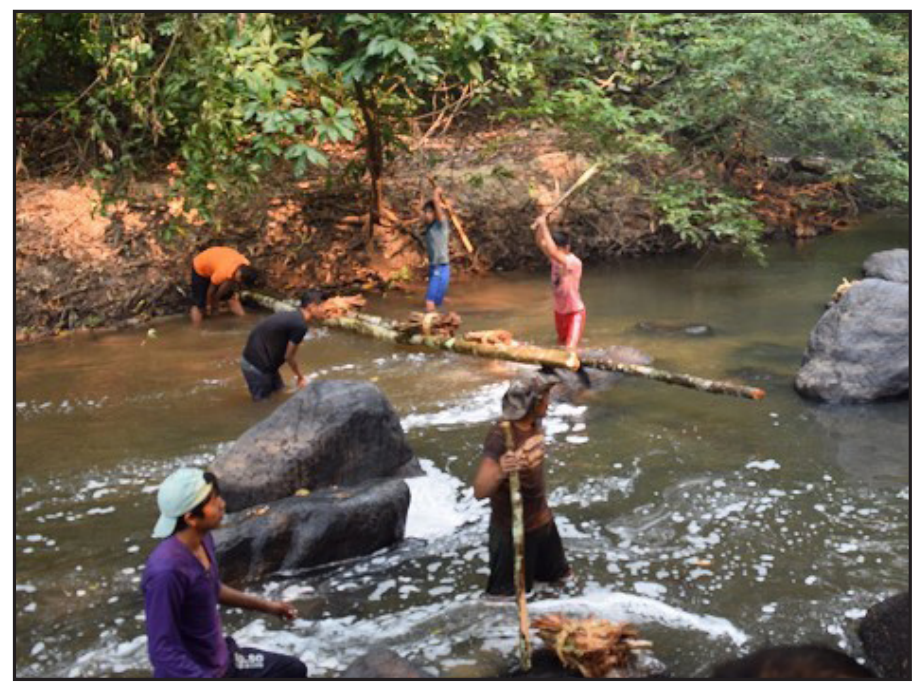

Fonte: Autores.

Como a pescaria de bater timbó é realizada coletivamente, ao fim de cada dia da pescaria, os peixes capturados e que foram guardados nos sacos de 60 kg são distribuídos, pelo mais velho, aos membros participantes, separados por família. Para fazer a distribuição dos peixes, eles são classificados por espécies, 
depois são colocados em sacos menores para cada membro participante receber a mesma quantidade. A separação dos peixes por espécie é realizada pelas muIheres, na mesma área que foi limpa pelos homens no início da pescaria. Todos assistem a essa etapa, em especial as crianças e os jovens. Os peixes separados são colocados sobre folhas de palmeira (Figuras 5(a) e 5(b)).

Figura 5 - Peixes coletados e distribuição aos membros participantes

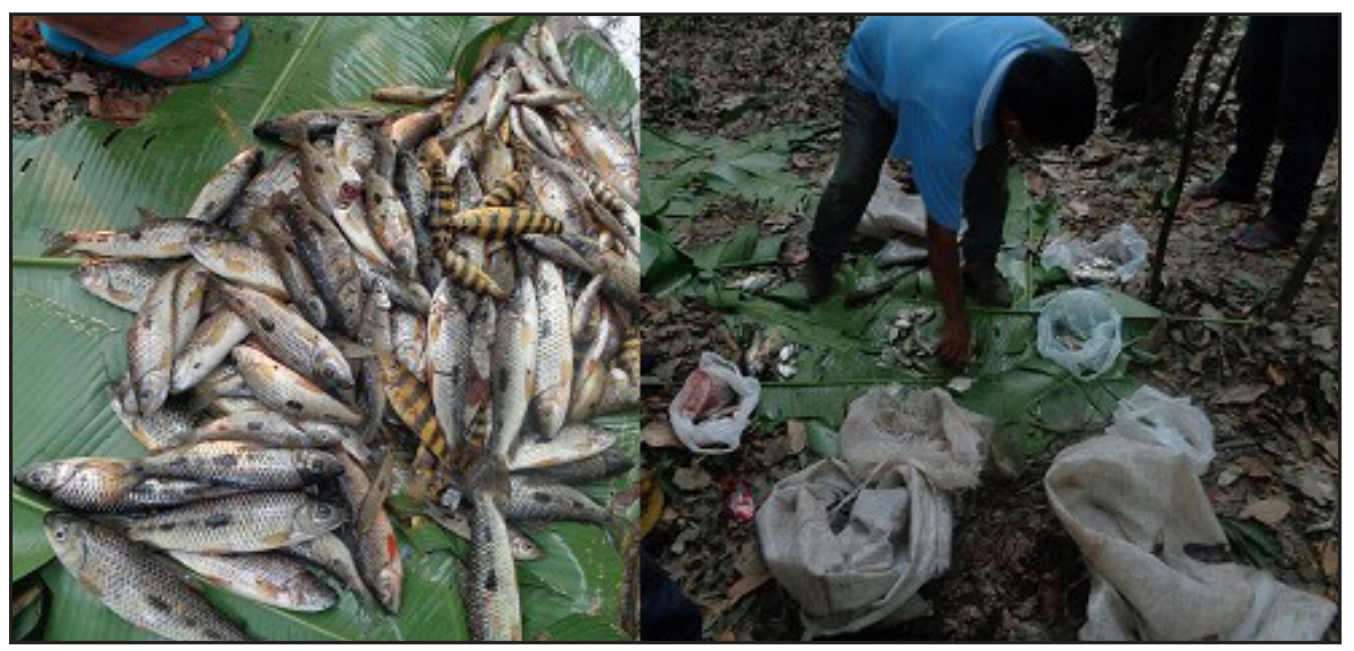

Fonte: Autores.

Um professor indígena que leciona para as crianças nos relatou que, em relação à divisão de peixes, ele pode pedir aos alunos para desenharem os diferentes tipos de peixes pescados, aproveitando para falar sobre a alimentação indígena e o porquê de pescarem em época de águas baixas, podendo explorar, ainda, os nomes dos peixes e como é o corpo deles. Constatamos que esse professor, em sua prática docente, pode utilizar a interdisciplinaridade, apropriando-se da educação artística para explorar conceitos de ciências, de forma a explanar sobre as diferentes características dos peixes, além de abordar sobre a alimentação indígena.

Essa prática é corroborada pelo Rcnei (BRASIL, 1998, p, 256), quando afirma que os povos indígenas "[...] podem aproveitar estudos sobre ambiente aquático, pois o rio e seu barranco são bons contextos para o estudo de água e solo, seres vivos da água e da mata de galeria", e isso é reforçado pelo Manual de Orientação para a Alimentação Escolar na Educação Infantil, Ensino Fundamental, Ensino Médio e na 
Educação de Jovens e Adultos (BRASIL, 2012, p. 29), quando este afirma que toda comunidade escolar deve estar envolvida "[...] nas atividades de educação alimentar e nutricional potencializando os resultados de tais ações". É importante ressaltar que os professores indígenas desenvolvem suas práticas baseados em sua experiência cotidiana na aldeia e naquilo que "experienciaram" na licenciatura intercultural.

Em geral, as famílias, após a pesca do timbó, preparam uma comida feita com os peixes, conhecida como caldeirada. É a hora da confraternização pela pesca realizada. Com relação ao preparo dessa comida, o mesmo professor indígena nos informou que aproveita para explicar aos alunos o que é utilizado e a importância dos ingredientes para a saúde deles. Além disso, aproveita para explorar outras receitas por eles utilizadas. Para isso, as crianças dizem o que seus familiares preparam à base de peixe, e ele aproveita para trabalhar a língua materna, conceitos de matemática envolvendo as quantidades utilizadas nas receitas, bem como falar sobre os festejos em que o peixe está presente.

Como pudemos constatar, a prática docente desse professor orienta-se por algumas legislações, como as Dcneei (BRASIL, 2012) e as Diretrizes Curriculares Nacionais para a Educação Básica (Dcneb) (BRASIL, 2013). De acordo com as Dcneei (BRASIL, 2012, p. 8), a organização curricular dos povos indígenas pode ser desenvolvida "por eixos temáticos, projetos de pesquisa, eixos geradores ou matrizes conceituais, em que os conteúdos das diversas disciplinas podem ser trabalhados numa perspectiva interdisciplinar". Essa mesma perspectiva é reforçada pelas Dcneb (BRASIL, 2013, p.) quando aborda a utilização da "interdisciplinaridade e contextualização na articulação entre os diferentes campos do conhecimento, por meio do diálogo transversal entre disciplinas diversas e do estudo e pesquisa de temas da realidade dos estudantes e de suas comunidades", auxiliando na elaboração de práticas docentes aliadas às do cotidiano da aldeia.

Em conversas com os professores indígenas de Matemática, Língua Materna e Cultura do Povo, bem como com os professores dos anos iniciais do ensino fundamental, da Escola Indígena Estadual Izidoro de Souza Meireles, da aldeia Paiter, Linha 09, soubemos de algumas atividades presentes em suas práticas docentes, relacionadas à pescaria de bater timbó. Tais atividades ratificam as ações dos tipos que descrevemos anteriormente, para o ensino em sala de aula, utilizando essa prática tradicional. O diretor da escola e professor indígena das disciplinas Língua Materna e Cultura do Povo, Gamalonô Surui, planeja com outros profes- 
sores indígenas os conteúdos que estão relacionados interdisciplinarmente com o bater timbó. De acordo com esse professor:

Em relação ao bater timbó trabalhado em sala de aula, eu tenho que planejar as aulas as quais disciplina que pode estar envolvido nessa atividade pra que o trabalho seja interdisciplinar, porque a escola indígena trabalha de forma interdisciplinar. Ela tá envolvida Matemática, Língua Materna, Cultura do Povo, Arte, tudo isso, Ciência, Geografia, História, todo esses disciplina citado está dentro do trabalho de bater timbó, que está envolvido na sala de aula. (Gamalonô Surui, 2018).

Segundo esse professor, a história da prática tradicional de bater timbó envolve vários assuntos da disciplina Cultura do Povo, como a arte com as pinturas corporais que eram realizadas pelos Paiter e as músicas cantadas pelo chefe do grupo depois do bater timbó. Também, na disciplina Língua Materna, são trabaIhados nomes das plantas envolvidas no bater timbó e nomes dos peixes, tanto na norma culta da língua Paiter quanto na linguagem popular.

A disciplina Cultura do Povo ela tá falando respeito da cultura tradicionais, atividade tradicionais do povo, a regra, todas as técnicas transmitido durante o bater timbó, mas tudo isso tem regulamento. Na Arte ele vai tá envolvido nas músicas, nas pinturas, e cada desenho das músicas ela é feito pelo chefe do grupo. E em relação à língua materna, o trabalho será dentro de todas aquela linguagem que os alunos não conhecem ainda. Existe uma linguagem culta, que assim como também na língua portuguesa, existe linguagem popular, como acontece na língua portuguesa. Então, a gente trabalha dentro dessas linguagem. Nome dos peixes que os alunos não conhece ainda a gente trabalhamos também. Hoje o jovem não sabe achar timbó. Nem aquela casca de árvore tamburi que a gente usa durante o processo de timbó, o jovem não sabe achar na mata. Então tudo isso trabalhamos na língua materna, principalmente os nomes, a importância de bater timbó para a cultura. Por que existe bater timbó? Como surgiu bater timbó? Tempo, duração de tempo do processo de bater timbó, quanto tempo leva, tudo isso a gente trabalha na língua materna. (Gamalonô Surui, 2018).

Já na alfabetização das crianças e nos anos iniciais do ensino fundamental, o professor indígena Garixamá Surui disse que utiliza o bater timbó. Ele corrobora a fala do professor Gamalonô, com respeito ao ensino das crianças em sala de aula, utilizando essa prática tradicional. Ele disse que trabalha com as crianças na sala de aula começando com os nomes dos materiais que eles têm que buscar 
para bater timbó. Em Ciências, ele trabalha os nomes das frutas de que os peixes se alimentam. Em Geografia, ele disse que trabalha qual o melhor local que eles acham que podem bater timbó. Em Língua Materna, ele disse trabalhar com a escrita dos nomes dos peixes. E a matemática em sala de aula também é trabalhada com o bater timbó: "dentro da matemática, a gente trabalha de estuda peixes, né, quais tipo do peixe que têm no rio, né, então ensina ele o nome do peixe, quanto tipo tem peixe". (Garixamá Surui, 2018).

Ainda com relação à matemática, o professor indígena de Matemática Mopidaor Surui informou que a atividade tradicional de bater timbó possibilita ao professor trabalhar em sala de aula com vários assuntos na disciplina Matemática. Números naturais, paridade de números inteiros, medidas de comprimento, conceitos de máximo e mínimo e operações numéricas de soma, subtração, multiplicação e divisão são alguns exemplos diretos relacionados ao bater timbó. De acordo com esse professor:

A gente Paiter não temos quantidade de pessoas certo que vai bater timbó, são várias quantidades. E outra coisa, quem for bater timbó, as pessoa são em duplas, no caso isso tá relacionado a números pares, porque cada um tem a sua dupla e não pode ter números ímpares. Então é infinita, né, quantidade de pessoas que vão ser trabalhada ali, e também a quantidade do timbó que foi cortada, que foi buscada na mata, são infinita em números também, porque a gente não tem quantidade certa pra bate timbó. E outra coisa, o timbó será só cortado em $40 \mathrm{~cm}$ o tamanho, e desses pedaço de 40 $\mathrm{cm}$, a quantidade máximo poderá ter 15 timbó, que onde a gente amarra e prepara pra bater. E temos o pau que vai bate o timbó, terá no máximo um metro de comprimento. São muitas coisas que tão envolvido da matemática aí, números naturais, números inteiro e outras coisa. Eu acredito que tem a área de multiplicação aí, porque a quantidade de pessoas que vão trabalha no bater timbó são que ganha os seus peixe, mais o dobro ou triplo mesmo da quantidade de pessoa que foi trabalhado ali. E outra coisa que pode ser também, toda vez que o líder, que ele dividia, né, as quantidade dos peixes pros trabalhadores, então ali tem uma divisão. Então há muitas outras coisa que pode ser trabalhada em cima de área de matemática ali. (Mopidaor Surui, 2018).

Assim, vemos que a prática piscatória tradicional de bater timbó possibilita trabalhar com vários conteúdos curriculares na escola indígena. Muitos conteúdos escolares foram ensinados utilizando essa prática, confirmados nos depoimentos de 
professores indígenas Paiter. Logo, o uso do bater timbó em sala de aula, além de fortalecer os conhecimentos culturais dos alunos, permite uma ressignificação de conteúdos escolares por meio de conhecimentos próprios, em especial, de matemática.

\section{CONSIDERAÇÕES FINAIS}

A utilização da cultura Paiter na escola indígena torna não só a sala de aula, mas toda a aldeia uma fonte de aprendizado e preservação das tradições da etnia. Ressignificar conteúdos escolares, como os de matemática, com a prática piscatória de bater timbó, reaviva os conhecimentos tradicionais inerentes aos indígenas e proporciona uma aprendizagem significativa para os alunos, ou seja, aquela aprendizagem em que as novas aquisições de conhecimento são baseadas e relacionadas, culturalmente, aos conhecimentos anteriores relevantes da estrutura cognitiva do educando (AUSUBEL, 2000). Dessa forma, os alunos indígenas não ficam atrelados somente à sala de aula, já que entendem que fora dela os saberes e fazeres da cultura indígena contêm conhecimentos empíricos, sejam matemáticos, sejam quaisquer outros, próprios do seu povo.

As possibilidades de ensino e de aprendizagem dos conteúdos escolares, mais especificamente os de matemática, que a prática piscatória de bater timbó apresenta, são inúmeras. Os Paiter Suruí percebem o potencial que a cultura deles tem, pois, nas atividades cotidianas, por mais simples que sejam, transbordam conhecimentos. Neste trabalho, utilizamos uma atividade desenvolvida pelo povo Paiter Suruí como suporte ao ensino e à aprendizagem da matemática escolar, bem como de outras disciplinas. Isso nos permite afirmar que é possível contextualizar os conteúdos matemáticos escolares com as práticas cotidianas de um povo para que os alunos ressignifiquem sua aprendizagem. Nessa lógica, constatamos que as práticas docentes relatadas estão em sintonia com o Programa Etnomatemática de D’Ambrosio (2011), quando este afirma que não tem como não contextualizar a matemática acadêmica e escolar com as manifestações culturais de povos tradicionais, que também são produtores de conhecimentos.

Entre as várias estratégias de natureza matemática que os povos indígenas utilizam em seu dia a dia, está a de estimar. Conforme podemos ver em Domite (2009), Mattos (2018), Mattos e Ferreira Neto (2019) e Mattos e Mattos (2019), os indígenas estão sempre estimando tempo, espaço, medidas e quantidades. 
Quer seja para saberem quando voltar da mata, quer seja para medirem o espaço que têm de limpar para fazerem sua horta, as dimensões internas de suas construções, a largura de seus rios, ou ainda para saberem a quantidade de comida e bebida em uma festividade. Observamos que essa estratégia etnomatemática de estimar está presente na atividade tradicional de bater timbó, como na limpeza da área na mata, na confecção da circunferência para colocar os pedaços de cipó e na distância até a rede no rio. De acordo com os professores indígenas Paiter, isso é utilizado em sala de aula, na educação escolar indígena.

A utilização de uma abordagem didático-pedagógica, baseada na Pedagogia de Projetos, "consiste em permitir que os estudantes confrontem as questões e os problemas do mundo real que considerem significativos, determinando como abordá-los e, então, agindo de forma cooperativa em busca de soluções" (BENDER, 2014, p. 9). Com esse entendimento, constatamos que o Projeto Mais Educação, desenvolvido na aldeia Paiter, possibilita ao professor indígena realizar a intersecção entre os conhecimentos culturais e acadêmicos com os escolares. São práticas docentes corroboradas pelo Rcnei (BRASIL, 1998), quando o referencial aborda que os currículos para as escolas indígenas devem ser ancorados em materiais específicos, elaborados por professores e alunos, e refletir a perspectiva intercultural de uma educação diferenciada.

Afirmamos haver aproximação entre a prática docente dos professores indígenas investigados com a cultura e a natureza circundante. Corroboramos D’Ambrosio (2008, p. 9), quando este constata que "ensinar a matemática ocidental nas comunidades indígenas é um desafio", mas que o ensino pode ser flexibilizado por introdução de práticas docentes diferenciadas, com o reconhecimento, por parte dos professores, das especificidades inerentes ao ensino e à aprendizagem dos conteúdos escolares, alguns distantes da realidade deles. Como eles mesmos afirmam, "ensinar a matemática do branco" torna-se mais eficaz quando contextualizada na própria cultura, reavivando conhecimentos tradicionais da etnia. Nessa perspectiva, é essencial promover a adequação das metodologias didático-pedagógicas às características das comunidades indígenas, cada qual com suas especificidades, respeitando, ainda, os modos próprios que os professores desenvolvem suas práticas docentes.

A observação desses critérios pelos órgãos responsáveis demanda certas condições para a elaboração de um currículo viável e centrado na realidade de cada povo 
indígena. Da mesma forma, a preparação de material didático específico deve ser de responsabilidade dos próprios indígenas. As ações colaborativas entre órgãos governamentais e os indígenas devem primar pela garantia dos direitos dos indígenas, pela autonomia na administração de suas escolas, possibilitando a legitimidade de suas práticas docentes para o reconhecimento e respeito às diferenças. Destacamos, ainda, que há necessidade de garantir a formação inicial e continuada dos professores indígenas e valorizar o exercício profissional deles. Consequentemente, para garantir os princípios da educação escolar indígena, esta deve constituir-se como um espaço de diálogo entre culturas, centrar-se em atividades que promovam o viver bem indígena e ter exclusividade de sua cultura sobre outras.

Possibilidades existem, como constatamos neste trabalho, de atividades centradas e organizadas por práticas socioculturais, inspiradas por professores indígenas que sentem a necessidade de facilitar a aprendizagem dos alunos indígenas. Observamos que os saberes e as práticas dos alunos indígenas ancoram outros conhecimentos, valorizando seus modos próprios de viver, sua oralidade e sua história. A articulação de projetos comunitários - que são desenvolvidos cotidianamente na aldeia - com os ensinamentos escolares reflete a autonomia desses professores para as diversas necessidades e dificuldades encontradas em sua prática docente.

Por fim, podemos afirmar que os pressupostos etnomatemáticos, enfatizados pela entrada, em sala de aula, dos saberes e fazeres gerados e difundidos por meio da cultura de um povo, empoderam seus membros, cultural, social, política e afetivamente (DOMITE, 2009). Por outro lado, ensinar e aprender tornam-se processos entrelaçados às tradições, saberes e fazeres da etnia, renovando-os e ressignificando-os para que o professor indígena tenha um novo olhar sobre eles.

\section{REFERÊNCIAS}

AUSUBEL, D. P. Aquisição e retenção de conhecimentos: uma perspectiva cognitiva. Lisboa: Plátano Edições Técnicas, 2000.

BENDER, W. N. Aprendizagem baseada em projetos: educação diferenciada para o século XXI. Porto Alegre: Penso, 2014.

BICHO, J. S. Etnomatemática e práticas pedagógicas: saberes matemáticos escolares e tradicionais na educação escolar indígena Karipuna. 2018. Tese (Doutorado em Educação em Ciências e Matemática) - Universidade Federal de Mato Grosso, Cuiabá, 2018. 
BRASIL. Ministério da Educação. Diretrizes Curriculares Nacionais para a Educação Básica. Brasília-DF: MEC, 2013. Disponível em: http://portal.mec.gov.br/docman/julho-2013pdf/13677-diretrizes-educacao-basica-2013-pdf/file. Acesso em: 7 jan. 2020.

BRASIL. Ministério da Educação. Manual de orientação para a alimentação escolar na educação infantil, ensino fundamental, ensino médio e na educação de jovens e adultos. 2. ed. Brasília: Pnae, 2012.

BRASIL. Ministério da Educação. Referencial Curricular Nacional para as Escolas Indígenas. Brasília: MEC, 1998. Disponível em: http://www.dominiopublico.gov.br/pesquisa/ DetalheObraForm.do?select_action=\&co_obra=26700. Acesso em: 7 jan. 2020.

BRASIL. Ministério da Educação. Lei 9.394 de 20 de dezembro de 1996. Estabelece as diretrizes e bases da Educação Nacional. Brasília: MEC, 1996. Disponível em: http://www. planalto.gov.br/ccivil_03/leis/L9394.htm. Acesso em: 7 jan. 2020.

BRASIL. Ministério da Educação. Diretrizes para a Política Nacional de Educação Escolar Indígena. Brasília: MEC, 1993. (Cadernos de Educação Básica, Série Institucional 2). Disponível em: http://www.dominiopublico.gov.br/download/texto/me001778.pdf. Acesso em: 07 jan. 2020.

BRASIL. Ministério da Educação. Portaria Interministerial MJ/MEC n. 559, de 16 de abril de 1991. Dispõe sobre a Educação Escolar para as populações indígenas. Brasília: MEC, 1991. Disponível em: https://cimi.org.br/2004/06/21816/. Acesso em: 7 jan. 2020.

BRASIL. Constituição da República Federativa do Brasil. Brasília: Senado Federal, 1988. Disponível em: http://www.planalto.gov.br/ccivil_03/constituicao/constituicaocompilado. htm. Acesso em: 7 jan. 2020.

CUNHA, A. C.; CUNHA, J. S. M. A formação de professores indígenas "Povos do Pantanal" e "Teko Arandu". In: MATTOS, S. M. N. (Org.). Currículo, formação e práticas docentes. Curitiba: CRV, 2018. p. 85-100.

D'AMBROSIO, U. Etnomatemática - elo entre as tradições e a modernidade. 4. ed. Belo Horizonte: Autêntica, 2011.

D’AMBRosio, U. O Programa Etnomatemática: uma síntese. Acta Scientiae. v. 10, n. 1, p. 7-16, 2008. Disponível em: www.periodicos.ulbra.br/index.php/acta/article/ download/74/66. Acesso em: 7 jan. 2020.

DOMITE, M. C. S. Perspectivas e desafios da formação do professor indígena: o formador externo à cultura no centro das atenções. In: FANTINATO, M. C. C. B. (Org.), 
Etnomatemática: novos desafios teóricos e pedagógicos. Niterói: Editora da Universidade Federal Fluminense, 2009. p. 181-92.

GALLOIS, D. T. (Org.). Patrimônio cultural imaterial e povos indígenas: exemplos no Amapá e norte do Pará. São Paulo: lepé, 2006.

GRUPIONE, L. D. B. (Org.). Índios no Brasil. Brasília: MEC, 1994.

MATTOS, S. M. N. O sentido da matemática e a matemática do sentido: aproximações com o programa etnomatemática. São Paulo: Editora Livraria da Física, 2020.

MATTOS, J. R. L.; FERREIRA NETO, A. Etnomatemática e educação escolar indígena Paiter Suruí. São Paulo: Editora Livraria da Física, 2019.

MATTOS, J. R. L.; FERREIRA NETO, A. O povo Paiter Suruí e a etnomatemática. In: BANDEIRA, F. A.; GONÇALVES, P. G. F. (Org.). Etnomatemáticas pelo Brasil: aspectos teóricos, ticas de matema e práticas escolares. Curitiba: CRV, 2016. p. 79-100.

MATTOS, S. M. N.; MATTOS, J. R. L. Etnomatemática e prática docente indígena: a cultura como eixo integrador. Hipátia, São Paulo, v. 4, n. 1, p. 102-15, jun. 2019.

MATTOS, S. M. N.; MATTOS, J. R. L. Preservação ambiental e cultural na educação escolar indígena. In: MATTOS, J. R. L.; MATTOS, S. M. N. (Org.). Etnomatemática e Práticas Docentes Indígenas. Jundiaí: Paco Editorial, 2018. p. 185-214.

MATTOS, J. R. L. Matemática e cultura em ação na educação escolar indígena. In: MATTOS, J. R. L.; MATTOS, S. M. N. (Org.). Etnomatemática e Práticas Docentes Indígenas. Jundiaí: Paco Editorial, 2018. p. 185-214.

MINDLIN, B. Diários da floresta. 1. Ed. São Paulo: Editora Terceiro Nome, 2006.

MINDLIN, B. Nós Paiter: os Suruí de Rondônia. Petrópolis: Editora Vozes, 1985.

ORGANIZAÇÃO DAS NAÇÕES UNIDAS. Declaração das Nações Unidas sobre os direitos dos povos indígenas - Drips. Rio de Janeiro: Unesco, 2008.

SAMPAIO, J. A. L. O "resgaste cultural" como valor: reflexões antropológicas sobre a formação dos professores indígenas. In: GRUPIONE, L. D. B. (Org.). Formação de professores indígenas: repensando trajetórias. Brasília: MEC/Unesco, 2006. p. 165-74.

SCANDIUZZI, P. P. Educação indígena x educação escolar indígena: uma relação etnocida em uma pesquisa Etnomatemática. São Paulo: Editora Unesp, 2009. 
VERGANI, T. Educação Etnomatemática: o que é? Natal: Flecha do Tempo, 2007.

YIN, R. K. Pesquisa estudo de caso - desenho e métodos. 2. ed. Porto Alegre: Bookman, 1994.

\section{Sobre os autores:}

JoséRobertoLinhares de Mattos: Pós-doutor em Educação pela Universidadede Lisboa. Professor do Programa de Doutorado da Rede Amazônica de Educação em Ciências e Matemática; do Programa de Pós-Graduação em Educação Agrícola da Universidade Federal Rural do Rio de Janeiro; e da Universidade Federal Fluminense. E-mail: mattos@campus.ul.pt, Orcid: http://orcid.org/0000-0002-4075-6764

Sandra Maria Nascimento de Mattos: Doutora em Educação pela Pontifícia Universidade Católica de São Paulo (PUC-SP)/Universidade Católica Portuguesa. Professora do Programa de Pós-Graduação em Educação Agrícola da Universidade Federal Rural do Rio de Janeiro. E-mail: smnmattos@gmail.com, Orcid: http://orcid.org/0000-0003-2622-0506

Gamalonô Surui: Mestre em Educação pela Universidade Federal Rural do Rio de Janeiro (UFRRJ). Professor da Escola Indígena Estadual Izidoro de Souza Meireles. E-mail: gmInsurui@gmail.com, Orcid: http://orcid.org/0000-0001-6576-5467

Recebido em 1으 de abril de 2020.

Aprovado para publicação em 5 de junho de 2020. 